\title{
Efetividade do princípio da economicidade na contratação de serviço de aluguel de veículos pela administração pública, realidade ou ficção?
}

\section{Effectiveness of the principle of economy in the contracting of vehicle rental services by the public administration, reality or fiction?}

\author{
Uilton De Oliveira Chagas ${ }^{1}$, Ronaldo André Bezerra Salton ${ }^{2}$, Marlene Valério Dos Santos \\ Arenas $^{3 *}$, Valmir Batista Prestes De Souza ${ }^{3}$
}

\begin{abstract}
RESUMO
O presente artigo analisa a efetividade do princípio da economicidade na contratação de serviço de aluguel de veículos pela administração pública. A pesquisa tem por objetivo geral analisar a efetividade e economicidade da contratação do serviço de aluguel de veículos em comparação ao serviço de manutenção de frota própria do IBAMA-Rondônia, no período de 2013 a 2016, assim sendo, buscou-se identificar e analisar o número de veículos disponíveis no serviço de locação, o custo do serviço e a sua média de custo de um veículo locado. Projetar os dados obtidos em comparação à aquisição, manutenção e utilização do veículo para análise da média de custo de frota própria. Trata-se de uma pesquisa quali/quanti de um estudo de caso realizado na Superintendência do IBAMA em Porto Velho, com pesquisa documental envolvendo a legislação e pesquisas eletrônicas. Os resultados mostram que há economicidade na locação de veículos, principalmente nos primeiros dois anos de contrato, aferindo somente pela questão de menor custo médio por quilômetro.
\end{abstract}

Palavras-chave: Locação; Aluguel; Contratação.

\section{ABSTRACT}

This article analyzes the effectiveness of the principle of economy in the contracting of vehicle rental services by the public administration. The research has the general objective to analyze the effectiveness and economy of hiring the vehicle rental service compared to the maintenance service of IBAMARondônia's own fleet, in the period from 2013 to 2016, therefore, we sought to identify and analyze the number of vehicles available in the rental service, the cost of the service and your average cost of a leased vehicle. Project the data obtained in comparison to the acquisition, maintenance and use of the vehicle to analyze the average cost of own fleet. This is a quali/quanti research of a case study carried out at the Superintendence of IBAMA in Porto Velho, with documental research involving legislation and electronic research. The results show that there is economy in vehicle leasing, especially in the first two years of the contract, measuring only the issue of lower average cost per kilometer.

Keywords: Lease; Rent; Contracting.

1 Instituto Federal de Rondônia (IFRO)

2 Instituto Brasileiro do Meio Ambiente e dos Recursos Naturais Renováveis (IBAMA)

3 Universidade Federal de Rondônia (UNIR)

*E-mail: marlenearenas@unir.br 


\section{INTRODUÇÃO}

Há um bom tempo que em muitos lugares do país, os gestores públicos têm optado pela locação de sua frota de veículos e relatando bons resultados desse serviço. Procedimento que tem sido uma solução utilizada há muito tempo no setor privado a exemplo de empresas como Ambev, Coca-Cola, Votorantim entre outros grandes grupos.

Além do tempo gasto com a administração e a manutenção de uma frota própria, deixando de se dedicar aos negócios para ter que cuidar da compra dos veículos, negociação, custos de aquisição, depreciação, licenciamento, multas, seguro, sinistros, cotação de oficinas, manutenção, conserto, documentação, administração da frota, veículos reservas, venda e aquela pecinha que deu um defeito e ninguém tem para vender.

Em abril de 2013 o Instituto Brasileiro do Meio Ambiente e dos Recursos Naturais Renováveis (IBAMA) assinou um contrato de locação de veículo do tipo caminhonete, para atender necessidade de locomoção em condições adversas que se reveste às operações do instituto, realizadas na maioria, no interior não desbravado dos estados brasileiros, em locais nem sempre dotados de facilidades de abastecimento e transporte verificado nos meios urbanos. A Superintendência de Rondônia do órgão locou 37 veículos versão Pick up, cabine dupla, quatro portas laterais, capacidade para transporte de cinco passageiros, incluindo o motorista, transmissão manual de no mínimo cinco, velocidades à frente e uma à ré, com tração traseira 4X2 e opção de acionamento manual do sistema 4X4, inclusive com marcha reduzida, direção com assistência hidráulica ou elétrica, entre outras características e acessórios. Dois itens foram licitados sendo no padrão II (com capota de fibra de vidro) e no padrão I (com capota marítima). Essa solução encontrada pela gestão do Instituto em Rondônia de substituir os veículos próprios por veículos alugados trouxe economia financeira efetiva ou redução dos custos para o Instituto?

A presente pesquisa tem por objetivo geral analisar a efetividade e economicidade da contratação do serviço de aluguel de veículos em comparação ao serviço de manutenção de frota própria do IBAMA na superintendência de Porto Velho, em Rondônia, no período de 2013 a 2016. Para atingir esse objetivo geral necessário se faz identificar e analisar o número de veículos disponíveis no serviço de locação, o custo do serviço, a média de custo de um veículo locado, projetar os dados obtidos em comparação à aquisição, manutenção e utilização do veículo para análise da média de custo de frota própria, verificar a economicidade do contrato de locação de veículos no Estado? 
A constante cobrança dos cidadãos por serviços públicos eficientes provoca nos gestores a preocupação em atender as necessidades sociais com o menor custo e maior efetividade. Nesse contexto, visto o valor expressivo gasto anualmente no Brasil com serviços de transporte, propõe-se, nesta pesquisa, mensurar as despesas com frota própria e com frota alugada. Esses dados podem servir como apoio na decisão dos agentes públicos quanto à solução de transporte mais adequada. Será utilizada a informação dos contratos do IBAMA de Rondônia, uma vez que utiliza veículos alugados atualmente e, em anos anteriores, mantinha veículos próprios.

\section{REFERENCIAL TEÓRICO}

Nesta seção foi necessário realizar uma revisão bibliográfica dos princípios constitucionais da efetividade, economicidade, também da composição de custo, regime de competência e como ocorre a depreciação dos veículos no setor público, para dar suporte a pesquisa.

\subsection{O princípio constitucional: efetividade e economicidade}

Nossa Constituição brasileira de 1988 trouxe importantes mudanças para a Administração Pública. A seção IX, que trata da fiscalização contábil, financeira e orçamentária, vem expressamente previsto o princípio da economicidade.

Art. 70. A fiscalização contábil, financeira, orçamentária, operacional e patrimonial da União e das entidades da administração direta e indireta, quanto à legalidade, legitimidade, economicidade, aplicação das subvenções e renúncia de receitas, será exercida pelo Congresso Nacional, mediante controle externo, e pelo sistema de controle interno de cada Poder (BRASIL, 1988).

O vocábulo economicidade, definido por Bugarin (1999), "trata-se da obtenção do melhor resultado estratégico possível de uma determinada alocação de recursos financeiros, econômicos e/ou patrimoniais em um dado cenário socioeconômico".

Bugarin (1999, p. 1.) ainda traz mais algumas importantes definições de outros importantes autores.

Régis Fernandes de Oliveira ${ }^{4}$ explica que "economicidade diz respeito a se saber se foi obtida a melhor proposta para a efetuação da despesa pública, isto é, se o caminho perseguido foi o melhor e mais amplo, para chegar-se à despesa e se ela fez-se com modicidade, dentro da equação custo-benefício" (BIGARIN, 1999, p.1)

\footnotetext{
${ }^{4}$ OLIVEIRA, Régis Fernandes de HORVATH, Estevão; e TAMBASCO, Teresa Cristina Castrucci. Manual de Direito Financeiro, São Paulo, Editora Revista dos Tribunais, 1990, p. 94.
} 
A Constituição e toda legislação pertinente preceituam a necessidade da observância dos princípios por parte da Administração Pública. "O texto constitucional inseriu no ordenamento jurídico parâmetro de natureza essencialmente gerencial, intrínseco à noção de eficiência, eficácia e efetividade" (BUGARIN,1999, p. 1). Diz-se então que, se antes a economicidade era algo lógico, ou seja, estava implícito, hoje ela é outro princípio constitucional a que todo administrador público fica obrigado a considerar.

No caso da economicidade, a variável a ser considerada é unicamente o custo. Já para analisar a questão da efetividade, mede-se o impacto real da gestão pública na população da sociedade. Segundo Palvarini (2010, p.8) "efetividade são os impactos gerados pelos produtos/serviços, processos ou projetos."

Palvarini (2010, p.9) traz ainda como subdimensão do princípio da eficiência o "Custo-efetividade" como sendo:

relação entre os insumos para a prestação de um determinado serviço ou elaboração de um produto e a efetividade, ou seja, entende-se pelo grau de contribuição de um programa ou ação na consecução de metas e objetivos de impacto fixados para reduzir as dimensões de um problema ou melhorar uma dada situação (PALVARINI, 2010, p.9).

\subsection{Composição dos custos}

Para análise dos custos se faz necessária utilização de métodos científicos que proporcionem confiabilidade e, ao mesmo tempo, sejam aceitos pela administração pública e coadunem com as normas vigentes na legislação brasileira.

BEUREN (1993), afirma que os métodos de custeio não se limitam apenas à avaliação dos estoques, mas constituem-se em ferramentas que fornecem subsídios importantes à avaliação de desempenho dos gestores, à taxa de retorno nas decisões de investimentos, a decisões do tipo comprar versus fabricar e à formação de preço de venda, entre outros. Dentre esses métodos, estão o custeio por absorção, o custeio variável, o custeio baseado em atividades e o método das seções homogêneas.

Megliorini (2012) esclarece que o custeio por absorção, o método das seções homogêneas e o custeio variável são considerados métodos tradicionais, visto que neles os produtos sejam geradores de custos e mais adequados a ambientes nos quais há a predominância dos custos com materiais diretos e mão de obra direta. 
De acordo com Santos (2009), o método de custeio por absorção é considerado básico para a avaliação de estoques pela contabilidade societária para fins de levantamento do balanço patrimonial e da demonstração do resultado do exercício. Este método segue os princípios contábeis, sendo o método formalmente aceito, como requerido pela legislação do imposto de renda para propósitos de lucro. Além disso, o custeio por absorção agrega todos os custos, tanto os diretos quanto os indiretos.

Megliorini (2012), afirma que enquanto no custeio por absorção (estruturado para atender às disposições legais) os custos fixos são rateados aos produtos, no custeio variável (estruturado para atender à administração da empresa) apenas os custos variáveis (que são os que variam de acordo com o volume de produção ou de acordo com alguma outra base estabelecida) irão compor o custo do objeto de custeio (bens ou serviços), sejam diretos ou indiretos.

Já o método das seções homogêneas (RKW) tem como principal característica a divisão da empresa em centros de custos. Bornia (2010), menciona que os centros de custos podem ser determinados em razão da localização, quando partes da empresa encontram-se em locais diferentes, do organograma da empresa, considerando que cada setor como um centro de custos; das responsabilidades, que são conferidas a cada gerente; e da homogeneidade, que influencia diretamente na qualidade da alocação dos custos aos bens ou serviços.

Kaplan e Cooper (1998), entre outros autores, defendem que um dos principais fatores que proporcionou o desenvolvimento do método do custeio baseado em atividades foi a insatisfação com os dados de custos, apurados pelos sistemas tradicionais que distorcem os custos dos bens ou serviços, atribuindo custos indiretos aos produtos, de acordo com bases de rateio arbitrárias (geralmente, horas de mão de obra direta, horas máquina ou custo de material).

Percebe-se, através desses autores a importância do controle dos custos pelas organizações, sejam elas públicas ou privadas. Em busca de uma ciência que permita o entendimento e o controle dos custos, tem-se a contabilidade de custos como ferramenta de controle do patrimônio público.

O custeio por absorção foi adotado pela legislação brasileira com o advento da Lei n. 6.404/1976 e alterações. O nome do método, provavelmente, decorre do fato de que, no Brasil, na década de 1970, somente existia este método conhecido como Custeio 
Variável (NASCIMENTO, 2001). Logo, como não havia outro método que utilizasse técnicas de absorção de custos, este acabou se tornando o mais conhecido.

Para Martins (2003, p. 24), Custeio por Absorção é o:

Método derivado da aplicação dos princípios de contabilidade geralmente aceitos [...] consiste na apropriação de todos os custos de produção aos bens elaborados, e só os de produção; todos os gastos relativos ao esforço de produção são distribuídos para todos os produtos ou serviços feitos (MARTINS, 2003, p.24).

Machado (2002) salienta que, no setor público, diferentemente do setor privado, não há a necessidade de se distinguir entre o custo dos serviços e as despesas do período. Essa separação é importante quando o objetivo da apuração do custo é a avaliação de estoques dos produtos que serão vendidos no próximo período. No setor público esta distinção é irrelevante, já que o objetivo é apurar o custo dos serviços públicos prestados no período, supondo-se a inexistência de serviços ou produtos em processamento e/ou acabados.

$\mathrm{Na}$ absorção, os custos são classificados em diretos e indiretos. Souza e Clemente (2007, p.27) expõem a diferença:

Classificam-se como custos diretos todos os que forem fácil e confiavelmente contáveis por unidade de produto. Um exemplo de custo direto é a matéria prima. Se os atributos de facilidade de contagem e confiabilidade de resultado não estiverem presentes, então os custos são classificados como indiretos. Um exemplo de custo indireto é o salário do supervisor industrial (CLEMENTE, 2007, p. 27).

Há também outra classificação dos custos que leva em consideração a relação entre o valor de um custo e o volume de atividade em uma unidade de tempo, custos fixos e variáveis. Entende-se "Custos Variáveis: são aqueles que aumentam conforme o aumento de sua produção. [...] Custos Fixos: independente de aumento ou de diminuição do volume produzido, permanecerão constantes." (MACIEL, BONACIM, VICARI, 2011, p 44).

Além do custo por absorção é abordado o cálculo de custo médio definido por Samuelson (1975, p.494) sendo "simplesmente o Custo Total dividido pelo número de unidades $q$ produzidas", assim, (CT/Km).

A maioria dos ativos imobilizados possui vida útil limitada, fazendo com que seu uso ocorra durante um prazo finito de períodos contábeis futuros. Desta maneira, o sistema contábil deve incluir, nos períodos contábeis em que o ativo for utilizado, a apropriação gradativa de seu valor como custo ou despesa sob a denominação de 
depreciação, dependendo da sua natureza (SILVA, 2009). Em função do desgaste natural pelo uso do bem, da obsolescência e da ação da natureza, com o passar do tempo, os veículos vão perdendo valor, sendo a perda reconhecida como depreciação, até atingirem o valor residual.

\subsection{Depreciação veículos aplicada ao setor público}

Para entender a depreciação de veículos aplicada ao setor público o Conselho Federal de Contabilidade (CFC), estabelece normas e dentre as editadas, destaca-se para o presente estudo,

a NBC T - 16.9 que estabelece critérios e procedimentos para o registro contábil da depreciação.

Carneiro (2012), descreve: (i) como depreciação reduz o valor dos bens tangíveis pelo desgaste ou perda de utilidade por uso, ação da natureza ou obsolescência; (ii) como valor bruto contábil, o valor do bem registrado na contabilidade, em uma determinada data, sem a dedução da correspondente depreciação, amortização ou exaustão acumulada; (iii) como valor depreciável, valor original de um ativo deduzido do seu valor residual, (iv) como valor líquido contábil, o valor do bem registrado na contabilidade, em determinada data, deduzido da correspondente depreciação, (v) como valor residual, o montante líquido que a entidade espera, com razoável segurança, obter por um ativo no fim de sua vida útil econômica, deduzidos os gastos esperados para sua alienação; e por fim (vi) como vida útil_econômica, o período de tempo definido ou estimado tecnicamente, durante o qual se espera obter fluxos de benefícios futuros de um ativo.

A depreciação de um ativo somente começa a ser calculada quando o item estiver em condições de uso e não cessa até que o bem tenha atingido o seu valor residual, mesmo que este se torne obsoleto, ou seja, retirado temporariamente de operação. (QUINTANA, et al. 2011).

Segundo o manual do Sistema Integrado de Administração Financeira (SIAFI) ${ }^{5}$ do Governo Federal que consiste no principal instrumento utilizado para registro, acompanhamento e controle da execução orçamentária, financeira e patrimonial, no qual, foi padronizados critérios a serem utilizados pelos órgãos da administração pública direta, autarquias e fundações públicas pertencentes ao orçamento fiscal e da seguridade social.

\footnotetext{
${ }^{5}$ Secretaria do Tesouro Nacional. SIAFI Manual.020330 - Depreciação, Amortização e Exaustão Na Adm. Dir. União, Aut. e Fund.Web. Disponível em: <http://manualsiafi.tesouro.fazenda.gov.br/>. Acessado em 29 jul 2017.
} 
Os referidos órgãos devem utilizar para determinação da vida útil econômica e valor residual dos bens do ativo, como segue o Quadro 1.

Quadro 1 - Tabela de Vida Útil e Valor Residual de Veículos Públicos

\begin{tabular}{|l|c|c|}
\hline BENS & VIDA ÚTIL (anos) & VALOR RESIDUAL (\%) \\
\hline Carros de Combate & 30 & 10 \\
\hline Veículos de tração mecânica & 15 & 10 \\
\hline Veículos diversos & 15 & 10 \\
\hline Veículos ferroviários & 30 & 10 \\
\hline
\end{tabular}

Fonte: adaptado do manual SIAFI

A NBC T 16.9 (CARNEIRO et al., 2012) apresenta três métodos de cálculo dos encargos de depreciação que podem ser adotados, como o método das quotas constantes utilizando-se da taxa de depreciação constante durante a vida útil do ativo, caso o seu valor residual não se altere. $\mathrm{O}$ método das somas dos dígitos que resulta em uma taxa decrescente durante a vida útil, ou ainda, o método das unidades produzidas que resulta em uma taxa baseada no uso ou produção esperados. Nesse caso, a vida útil do bem é determinada pela capacidade de produção.

Para o setor público, o manual do SIAFI orienta que o método de depreciação deve ser compatível com a vida útil econômica do ativo e aplicado uniformemente durante esse período, sendo o cálculo dos encargos de depreciação a ser utilizado para toda a administração pública direta e indireta é o das quotas lineares ou constantes, já que a informação deve ser consistente e comparável, devendo constar em notas explicativas. As empresas públicas e sociedades de economia mista devem seguir a Lei no 6.404/76. Com exceção para casos particulares, segundo Quintana et al. (2011), devidamente justificados, pode-se utilizar outros métodos como método das unidades produzidas, do contrário, a depreciação do bem é calculada dividindo-se valor total pelo tempo de vida útil estimada. A Setorial Contábil do Órgão Superior pode estabelecer prazos de vida útil e taxas anuais diferentes, de maneira a refletir o melhor valor contábil possível para o registro da depreciação.

No setor privado, segundo Warren (2010), os recursos físicos pertencentes e utilizados por uma empresa que são permanentes ou têm vida útil prolongada são chamados de ativo imobilizado ou ativo fixo. É importante notar que o valor de mercado de um item de ativo imobilizado geralmente difere de seu valor contábil. Isso acontece porque a depreciação é um método de alocação, não um método de avaliação. 
A perda mensal ou anual é chamada de despesas com depreciação, que, obviamente, diminui o resultado do exercício. Athar (2005, p. 112) ressalta que, "as empresas brasileiras, em sua maioria, adotam os períodos aceitos ou recomendados pela legislação do imposto de renda", conforme mostrado no Quadro 2 a seguir:

Quadro 2 - Tabela de Vida Útil Setor Privado

\begin{tabular}{|l|r|r|}
\hline $\begin{array}{l}\text { BENS DO ATIVO } \\
\text { IMOBILIZADO }\end{array}$ & $\begin{array}{l}\text { TEMPO DE VIDA } \\
\text { ÚTIL }\end{array}$ & TAXA DE DEPRECIAÇÃO \\
\hline Móveis e utensílios & 10 anos & $10 \%$ a.a. \\
\hline Edifícios e construções & 25 anos & $4 \%$ a.a. \\
\hline Ferramentas & 20 anos & $5 \%$ a.a. \\
\hline $\begin{array}{l}\text { Máquinas, equipamentos, } \\
\text { instalações. }\end{array}$ & 10 anos & $10 \%$ a.a. \\
\hline Veículos & 5 anos & $20 \%$ a.a. \\
\hline Tratores e ambulâncias & 4 anos & $25 \%$ a.a. \\
\hline
\end{tabular}

Fonte: adaptado de Athar (2005, p. 113)

Por esse método (CREPALDI 2013, p. 228) "podemos calcular a depreciação mensal, trimestral ou anual, com ou sem valor residual", o qual é o valor estimado que não será depreciado e corresponderá ao preço de venda do bem como sucata, quando estiver imprestável ou obsoleto.

\subsection{Regime de competência}

Na contabilidade aplicada ao setor público, destaca Haddad e Mota (2010, p. 67) que "na questão orçamentária aplica-se a regra da competência em sua integralidade, ou seja, tanto na receita quanto na despesa."

Regime de competência é um método de registro de lançamentos contábeis, que é realizado no período de competência da receita ou despesa realizada. Haddad e Mota (2010, p. 67) explica que "a aplicação da competência impõe reconhecer as transações e os eventos na ocorrência dos respectivos fatos geradores, independentemente do seu pagamento ou recebimento", a mesma será registrada na data e no mês exato da transação efetuada. Tem como principal função organizar as finanças e prever o futuro financeiro da empresa.

Para compormos custo do veículo por custeio por absorção, além de levar em conta a depreciação mensal do ativo imobilizado, as despesas com a aquisição do veículo devem ser registradas, segundo o regime de competência, os efeitos financeiros das 
transações e eventos nos períodos nos quais ocorrem, independentemente de terem sido recebidos ou pagos. Portanto, proporcionam o tipo de informações sobre transações passadas e outros eventos, que são de grande relevância na tomada de decisões econômicas.

\section{PROCEDIMENTOS METODOLÓGICOS}

Propõe-se desenvolver um estudo da frota locada pelo Instituto Brasileiro do Meio Ambiente e dos Recursos Naturais Renováveis (IBAMA), superintendência de Porto Velho, no Estado de Rondônia, fazendo uma pesquisa documental para avaliar o custo médio por quilômetro rodado dos veículos utilizados pela autarquia entre os anos de 2013 a 2016.

Trata-se de um estudo de caso, cuja pesquisa foi realizada a partir do levantamento das informações através de pesquisa documental. Gil (2002, p.88) esclarece que, na pesquisa documental "exige a consulta aos mais diversos tipos de arquivos públicos e particulares”. Para tanto, a análise documental e documental online será realizada nos editais publicados, contratos e aditivos firmados pelo IBAMA para locação de veículos do tipo caminhonete, bem como documentos de controle e fiscalização do órgão.

Mesmo Gil (2002, p.137) afirmando que "não há consenso por parte dos pesquisadores quanto às etapas a serem seguidas" no desenvolvimento do estudo de caso, apresenta um conjunto de etapas utilizadas neste trabalho e seguidas nas maiorias das pesquisas: formulação de problema; definição da unidade-caso; coleta de dados; avaliação e análise dos dados; e preparação do relatório.

Dentro do estudo de caso, em uma segunda etapa, através de projeções contábeis, optamos por delinear a previsão de custo utilizando o método custeio por absorção definida por Megliorini (2012). Por fim, em uma abordagem quantitativa, analisaremos os resultados da pesquisa verificando o custo médio por quilômetro rodado, segundo definição de Samuelson (1975), de um veículo locado em comparação ao veículo de frota própria podendo constatar a real efetividade do princípio da economicidade, ou não, nos contratos de locação de veículos realizados pela organização estudada.

O custeio por absorção atende aos princípios do regime de competência e da depreciação. A depreciação é um importante fator analisado no cálculo de custo que, por padrão é lançado por ano, mas para efeito de comparação, proporcionamos mês a mês, atendendo ao regime de competência. 
O regime de competência, aplicado ao custeio por absorção, a despesa com aquisição do veículo, trocas futuras de pneus, troca de óleo, velas, e qualquer outra despesa presente ou futura é lançado também mês a mês nos períodos que competem. $\mathrm{O}$ resultado é um custo médio e constante.

\section{ANÁLISE DOS DADOS E RESULTADOS}

A pesquisa foi realizada no Instituto Brasileiro do Meio Ambiente e dos Recursos Naturais Renováveis (IBAMA), que é uma autarquia federal criada pela Lei no 7.735 de 22 de fevereiro de 1989, vinculada ao Ministério do Meio Ambiente (MMA), cujos objetivos são: a preservação, a melhoria e a recuperação da qualidade ambiental; assegurar o desenvolvimento econômico e; uso sustentável dos recursos naturais.

Com efeito, possui a responsabilidade pela execução da Política Nacional do Meio Ambiente, estabelecida pela lei $n^{\circ}$ 6.938/81, além da atribuição, ao nível federal, de conceder ou não licenciamento ambiental de empreendimentos, ao controle da qualidade ambiental, à autorização de uso dos recursos naturais (água, flora, fauna, solo etc.).

O IBAMA também tem a responsabilidade de fiscalização, monitoramento e controle ambiental e, em prol dessa necessidade, firmou contrato $\mathrm{n}^{\circ} 12 / 2013$, pactuado pela Diretoria de Planejamento, Administração e Logística (Diplan), sediada em Brasília, para atender a demanda de todo o território brasileiro, no qual está previsto a locação de 292 veículos para a Amazônia legal, sendo que 266 são do padrão I, locado por R\$ 5.639,09; 26 veículos do padrão II foram locados por $\mathrm{R} \$ 6.250,00$, para atender necessidade de locomoção em condições adversas que se revestem às operações do instituto, realizadas na maioria das vezes, no interior, de difícil acesso, e muitas vezes com dificuldade de abastecimento e transporte. A Superintendência do IBAMA em Rondônia, de acordo com o contrato, utiliza 37 veículos, sendo dois no padrão II e 35 no padrão I.

Entretanto, apenas 23 veículos padrão I se encontram na Sede da Superintendência em Porto Velho, enquanto que os outros 12 distribuídos no interior do Estado, sendo assim, não foi possível ter acesso aos dados dos veículos localizados no interior. Por meio de pesquisa documental do IBAMA, foi possível aferir a quilometragem de vinte e três veículos do padrão I. Os documentos possuem nove meses de registro, sendo de janeiro a abril e agosto a dezembro, de zero até $24.359,00 \mathrm{~km}$ rodados no mesmo mês. Foram 
270.661,00 quilômetros totalizados de 134 registro de meses utilizados, que, aplicando a fórmula (SAMUELSON, 1975, p. 494):

$$
\text { Custo Médio }=\frac{\text { Custo total }}{\text { produçiono }}=\frac{C T}{q}=C M \epsilon
$$

Assim, temos 270.661,00Km/134 M que resulta em uma CMe de 2.019,86 Km/M (quilômetros rodados por mês).

Tendo essa média como base, podemos já calcular o valor do veículo locado por seu V/Km, sabendo que, o custo do veículo locado é de R \$ 5.639,09 (cinco mil, seiscentos e trinta e nove reais e nove centavos), temos a expressão $\mathrm{R} \$ 5.639,09 / 2.019,86 \mathrm{~km}$, que nos resulta em $\mathrm{R} \$ 2,79 / \mathrm{km}$ rodado.

Para especificação dos outros custos foi levado em conta o rigor com que o veículo é utilizado. Itens como consumo, alinhamento, troca de pneus, amortecedores e freios, sofrem desgastes severos, mas, mesmo diante disso, os valores foram utilizados de forma padrão, como segue no Quadro 3.

Quadro 3 - Custos Variáveis

\begin{tabular}{|c|c|c|c|c|c|c|c|c|}
\hline Distância Percorrida por mês & $2.019,86$ & $\mathrm{~km}$ & & & & & & \\
\hline Custos Variáveis & \multicolumn{2}{|c|}{ Quilometragem } & \multicolumn{2}{|c|}{ Preço } & \multicolumn{2}{|c|}{ Total Mensal } & \multicolumn{2}{|c|}{ Total Anual } \\
\hline Alinhamento / Balanceamento & 10.000 & $\mathrm{~km}$ & $\mathrm{R} \$$ & 150,00 & $\mathrm{R} \$$ & 30,30 & $\mathrm{R} \$$ & 363,57 \\
\hline Consumo de combustível & 8 & $\mathrm{~km} / \mathrm{litro}$ & $\mathrm{R} \$$ & 3,00 & $\mathrm{R} \$$ & 757,45 & $\mathrm{R} \$$ & $9.089,37$ \\
\hline Freios & 25.000 & $\mathrm{~km}$ & $\mathrm{R} \$$ & 400,00 & $\mathrm{R} \$$ & 32,32 & $\mathrm{R} \$$ & 163,19 \\
\hline Troca de Amortecedores & 40.000 & $\mathrm{~km}$ & $\mathrm{R} \$$ & 902,00 & $\mathrm{R} \$$ & 45,55 & $\mathrm{R} \$$ & 546,57 \\
\hline Troca do Filtro do Óleo & 10.000 & $\mathrm{~km}$ & $\mathrm{R} \$$ & 69,00 & $\mathrm{R} \$$ & 13,94 & $\mathrm{R} \$$ & 167,24 \\
\hline Troca de Óleo & 10.000 & $\mathrm{~km}$ & $\mathrm{R} \$$ & 484,00 & $\mathrm{R} \$$ & 97,76 & $\mathrm{R} \$$ & $1.173,13$ \\
\hline Troca de Filtro do Combustível & 10.000 & $\mathrm{~km}$ & $\mathrm{R} \$$ & 90,93 & $\mathrm{R} \$$ & 18,37 & $\mathrm{R} \$$ & 220,40 \\
\hline Troca de Pneus & 40.000 & $\mathrm{~km}$ & $\mathrm{R} \$$ & $3.000,00$ & $\mathrm{R} \$$ & 151,49 & $\mathrm{R} \$$ & $1.817,87$ \\
\hline Troca do Filtro de $\mathrm{Ar}$ & 10.000 & $\mathrm{~km}$ & $\mathrm{R} \$$ & 79,41 & $\mathrm{R} \$$ & 16,04 & $\mathrm{R} \$$ & 192,48 \\
\hline Troca de Velas & 100.000 & $\mathrm{~km}$ & $\mathrm{R} \$$ & 597,00 & $\mathrm{R} \$$ & 12,06 & $\mathrm{R} \$$ & 144,70 \\
\hline Totais & & & & & $\mathbf{R} \$$ & $1.175,26$ & $\mathbf{R} \$$ & $13.878,54$ \\
\hline
\end{tabular}

Fonte: elaborado pelos autores.

Os custos fixos foram levantados baseados no que o IBAMA realmente pagaria caso possuísse um veículo próprio, pois diferentemente de uma empresa privada, não há incidência do imposto sobre propriedade de veículos automotores (IPVA). De acordo com o art. 150, VI, alínea a da Constituição Federal, a imunidade recíproca, sem prejuízo de outras garantias asseguradas ao contribuinte, impede que a União, os Estados, o Distrito Federal e os Municípios instituam impostos sobre o patrimônio, a renda ou serviços, uns dos outros.

Art. 150. Sem prejuízo de outras garantias asseguradas ao contribuinte, é vedado à União, aos Estados, ao Distrito Federal e aos Municípios: 
$(\ldots)$

VI - instituir impostos sobre: a) patrimônio, renda ou serviços, uns dos outros;(BRASIL, 1988)

A imunidade prevista no art. 150, VI, "a" da Constituição é estendida às autarquias, na forma do $\S 2^{\circ}$ daquele artigo, "no que se refere ao patrimônio, à renda e aos serviços, vinculados a suas finalidades essenciais ou às delas decorrentes". Outrossim, o seguro não seria contratado; não haveria despesas adicionais com estacionamento; e não há pedágio na região. Assim, seguro, estacionamento e pedágio não foram calculados, como pode ser observado no Quadro 4 a seguir

Quadro 4-Custos Fixos

\begin{tabular}{lrrrr}
\hline Custos Fixos & \multicolumn{2}{c}{ Anual } & \multicolumn{2}{c}{ Mensal } \\
\hline Seguro Obrigatório & RS & 105,81 & RS & 8,82 \\
\hline Licenciamento & RS & 120,64 & RS & 10,05 \\
\hline Lavagem & RS & $1.920,00$ & RS & 160,00 \\
\hline Totais & & & & \\
\hline
\end{tabular}

Fonte: elaborado pelos autores

Na composição do custo do veículo de uma frota própria, no Quadro 5 levou-se em conta que a contabilidade aplicada ao setor público adota para o registro das despesas o princípio de regime de competência, sendo assim, mesmo que a aquisição do veículo seja à vista, o valor é dividido nos custos do veículo. Em análise do contrato realizado entre a empresa vencedora da licitação e o IBAMA, dentre as exigências do contrato, há a cláusula que exige da contratada a troca de veículo após dois anos de uso ou 100.000 $\mathrm{km}$ rodados, o que vier primeiro. Logo, foi dividido o valor de investimento de aquisição do bem em dois anos para que seja possível a análise mensal do custeio por absorção.

Quadro 5 - Regime de competência

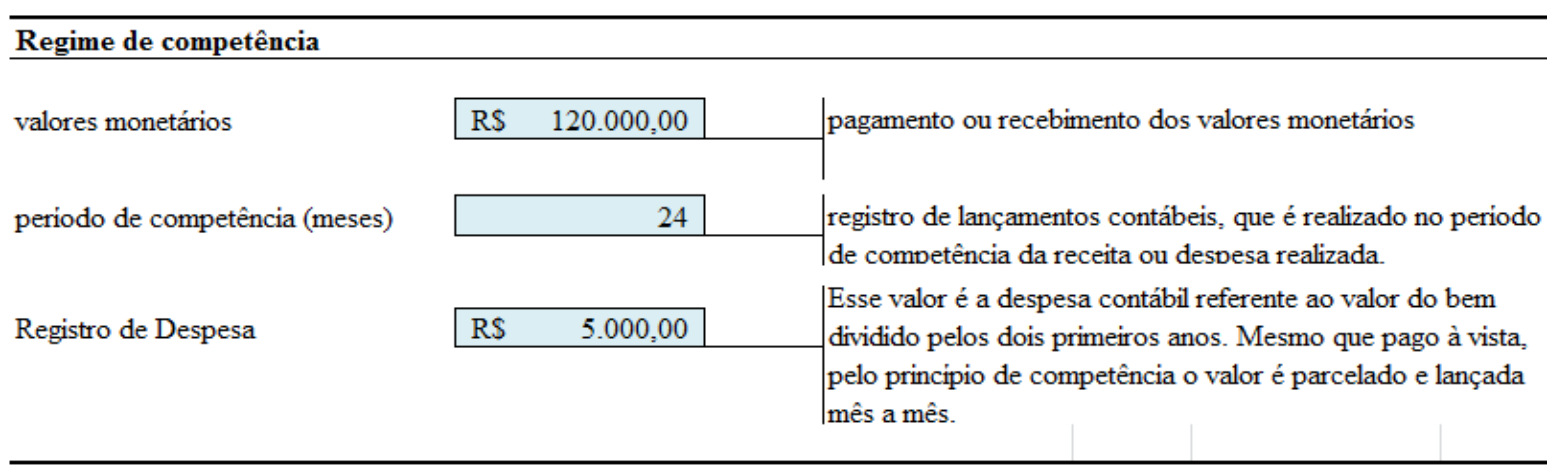

Fonte: elaborado pelos autores 
No Quadro 6, com o valor residual fixado em 10\%, como demonstrado no Quadro 1, pode-se utilizar a depreciação linear, dividindo $90 \%$ do valor do bem pela vida útil estabelecida no manual do SIAFI que é de 15 anos. Resultando assim, no valor de R\$ 7.200,00 ao ano de depreciação, ou seja, R \$ 600,00.

Quadro 6 - Cálculo da depreciação

\begin{tabular}{|c|c|c|c|}
\hline \multicolumn{4}{|l|}{ Deprecisação Linear } \\
\hline Preço do Carro & RS & $120.000,00$ & Preço do veículo novo. \\
\hline & & $10,00 \%$ & \multirow[t]{2}{*}{ Porcentagem de valor residual segundo o manual do SIAFI. } \\
\hline \multirow[t]{3}{*}{$\underline{\text { Porcentagem de valor residual }}$} & & & \\
\hline & RS & $12.000,00$ & \multirow{2}{*}{$\begin{array}{l}\text { o valor residual é um termo usado para definir o valor de um } \\
\text { ativo que sofre depreciação, ao final de sua vida útil. }\end{array}$} \\
\hline & & & \\
\hline Valor depreciável & RS & $108.000,00$ & $\begin{array}{l}\text { Este valor substituirá o valor original do bem para efeito do } \\
\text { cálculo da depreciação. }\end{array}$ \\
\hline Depreciação anual & RS & $7.200,00$ & $\begin{array}{l}\text { Este valor resulta da divisão do valor depreciável em } 15 \text { anos. } \\
\text { Tempo estipulado pelo manual SIAFI. }\end{array}$ \\
\hline
\end{tabular}

Fonte: elaborado pelos autores

A Quadro 7 apresenta os totalizadores de custos que somados descrevem o total de custo mensal do veículo que rodou uma média de 2.019,86 km em um mês, totalizando $\mathrm{R} \$ 7.114,13$. Assim, aplicando-se a mesma fórmula utilizada anteriormente para obter o CMe do veículo locado, ou seja, $\mathrm{R} \$ 7.114,13$ / 2.019,86 km, que nos resulta em $\mathrm{R} \$$ $3,52 / \mathrm{km}$ por quilômetro rodado.

Quadro 7 - Resultados dos custos

\begin{tabular}{|c|c|c|c|c|}
\hline \multicolumn{5}{|l|}{ Resultados } \\
\hline Descricão & Totais & & Custo / Preco do Carro & \\
\hline Custo Variável Mensal & & $1.175,26$ & $0,98 \%$ & Fixos x Variáveis \\
\hline Custo Fixo Mensal & RS & 338,87 & $0,28 \%$ & \\
\hline Desvalorizão Mensal do Carro & & 600,00 & $0,50 \%$ & - Custos Variáveis \\
\hline Parcela do Regime de Competência & RS & $5.000,00$ & $4,17 \%$ & Wustos Fixos \\
\hline Total da Despesa Mensal & RS & $7.114,13$ & $5,93 \%$ & \\
\hline Valor por quilometro rodado & RS & 3,52 & & $\begin{array}{l}\text { O valor do quilometro rodado é extraido da divisão do } \\
\text { Total da Despesa Mensal dividido pela média de } \\
\text { quilometros obtida no inicio da pesquisa. }\end{array}$ \\
\hline
\end{tabular}

Fonte: elaborado pelos autores

O Quadro 8 nos mostra a comparação dos resultados juntamente com um gráfico de barras, para dar melhor visibilidade da diferença de valores. 
Pode-se observar claramente que a locação de veículos gera uma economia para o órgão locador, observando-se somente a questão do custo por km dos veículos. Porém, a pesquisa também mostra que os valores se alteram ao longo do tempo. Após dois anos, trocando-se a frota e liquidando o bem, o órgão poderia ter um retorno de capital, pois esse procedimento está sendo levantado como hipótese.

Quadro 8 - Custos totais



Fonte: elaborado pelos autores

Segundo a Fundação Instituto de Pesquisas Econômicas (FIPE) ${ }^{6}$ que disponibiliza mensalmente, após realizar pesquisas de mercado, uma tabela de referência para os preços médios dos veículos no mercado nacional, o valor do veículo após dois anos de uso tem uma média de desvalorização do valor de $25 \%$. Se o IBAMA trocar a frota após dois anos, seria por meio de leilão do veículo, o qual, provavelmente, alcançaria no máximo o valor de $70 \%$ a $80 \%$ do valor da tabela FIPE.

Por inferência, podemos projetar um retorno de $70 \%$ de capital e reaplicar o valor para aquisição de uma nova frota, visando ter sempre o veículo em condições essenciais à execução das atividades do órgão. A disponibilidade do bem é de extrema importância, e se justifica a exigência de periodicidade de sua renovação.

No Quadro 9 a partir do segundo ano, os custos da frota própria passariam a contar com uma despesa do regime de competência em torno de $70 \%$ menor que os anos anteriores. Se mantiver as mesmas variáveis e alterar somente a parcela do capital empregado, o custo por quilômetro altera significativamente.

Quadro 9 - Resultados após dois anos e renovação da frota

6 FIPE. Fundação Instituto de Pesquisa Econômica. http://www.fipe.org.br/pt-br/home , acessado em 06/07/2017. 


\begin{tabular}{|c|c|c|c|c|}
\hline \multicolumn{5}{|l|}{ Resultados } \\
\hline Descricão & Totai & & Custo / Preco do Carro & \\
\hline \multirow{7}{*}{$\begin{array}{l}\text { Custo Variável Mensal } \\
\text { Custo Fixo Mensal } \\
\text { Desvalorizão Mensal do Carro } \\
\text { Parcela do Regime de Competência } \\
\text { Total da Despesa Mensal } \\
\text { Valor por quilometro rodado }\end{array}$} & & $1.175,26$ & $0,98 \%$ & Fixos $x$ Variáveis \\
\hline & & 338,87 & $0,28 \%$ & \\
\hline & & 600,00 & $0,50 \%$ & - Custos Variáveis \\
\hline & & $1.500,00$ & $1,25 \%$ & Wustos Fixos \\
\hline & $\mathrm{RS}$ & $3.614,13$ & $3,01 \%$ & \\
\hline & RS & 1,79 & & \multirow{2}{*}{$\begin{array}{l}\text { O valor do quilometro rodado é extraido da divisão do } \\
\text { Total da Despesa Mensal dividido pela média de } \\
\text { quilometros obtida no inicio da pesquisa. }\end{array}$} \\
\hline & & & & \\
\hline
\end{tabular}

Fonte: elaborado pelos autores

No Quadro 10, com esse novo cenário, após o segundo ano e renovação da frota, pode-se ter uma nova comparação dos resultados.

Quadro 10 - Comparação após dois anos e renovação da frota

\begin{tabular}{|c|c|c|c|c|}
\hline \multicolumn{3}{|c|}{ Valor por quilometro rodado } & \multirow{3}{*}{$\begin{array}{l}\text { R } \$ 3, \infty 0 \\
\text { R\$ } 2,50\end{array}$} & \multirow{7}{*}{$\begin{array}{l}\text { |- Locado } \\
\text { |- Próprio }\end{array}$} \\
\hline Modelo de frota & & $\mathrm{V} / \mathrm{Km}$ & & \\
\hline \multirow{3}{*}{ Locado } & & & & \\
\hline & RS & 2,79 & $R \$ 2, \infty$ & \\
\hline & RS & 1,79 & $\begin{array}{l}R \$ 1,50 \\
R \$ 1, \infty\end{array}$ & \\
\hline Próprio & & & $R S 0,50$ & \\
\hline Diferença & & $36 \%$ & & \\
\hline
\end{tabular}

Fonte: elaborado pelos autores

No Quadro 11, outro resultado que também foi possível verificar nesta pesquisa e veio como fator surpresa, é a mudança de perspectiva com a variação da utilização do bem dentro do mês. Quanto maior a distância percorrida pelo veículo, mais vantajoso é o contrato de locação, mesmo sobre o cenário apresentado no Quadro 7. Em uma projeção hipotética, mas não irreal, de uma média de 3.500,00 km rodados por mês, a diferença de custo por km é de $21 \%$ do veículo locado para o da frota própria.

Quadro 11 - Resultados após dois anos e com 3.500,00 km por mês em média simples

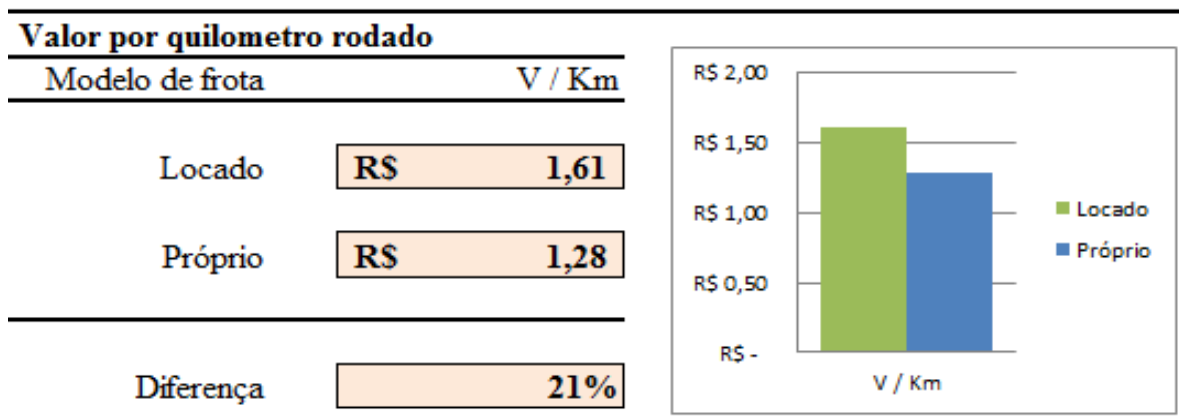


Da mesma forma, no Quadro 12, em uma inversão do cenário, computando uma quilometragem média menor como, por exemplo, de 1.000,00 km por mês, além dos custos se elevarem para as duas modalidades de frota, tanto locada como própria, a diferença, com as mesmas variáveis, é de $46 \%$ do bem locado em relação ao bem público próprio após a renovação da frota.

Quadro 12 - Resultados após dois anos e com 1.000,00 km por mês em média simples

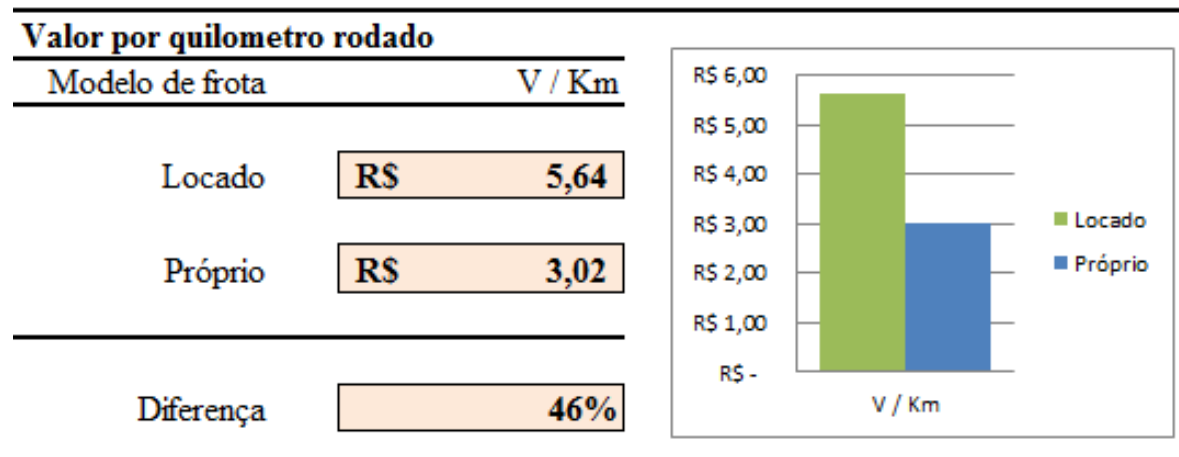

Fonte: elaborado pelos autores

Entretanto, há diversos fatores de custo que não estão sendo levados em consideração nessa pesquisa, pois, o contrato de locação firmado pela empresa vencedora e o IBAMA contempla vantagens que não poderão ser mensuradas nesta pesquisa, como o seguro, carro reserva, etc. Essas e outras vantagens da locação de veículos devem ser levadas em consideração. Contudo, fica como sugestão para possíveis pesquisas futuras.

\section{CONSIDERAÇÕES FINAIS}

O serviço de transporte na esfera pública é responsável por grande parte dos custos da máquina administrativa. Devido à política de transparência e a exigência social de responsabilidade na aplicação de recursos públicos, os administradores têm implementado novas estratégias em soluções mais efetivas e econômicas. A terceirização de serviços tem sido utilizada em vários setores da economia como alternativa de solução dos problemas sociais. 
Nesta pesquisa, foram analisados os custos com veículo próprio e com veículo alugado no IBAMA em Rondônia, na superintendência de Porto Velho. Para tanto, foi utilizado o custeio por absorção e a metodologia do SIAFI para a avaliação e depreciação de patrimônio. Os dados foram obtidos através de análise documental, bem como através de pesquisas junto à concessionária autorizada do veículo utilizado em Porto Velho.

Após a análise dos dados, verificou-se o custo de $\mathrm{R} \$ 2,79 / \mathrm{km}$ rodado em veículos alugados. Para veículos próprios o custo encontrado foi de $\mathrm{R} \$ 3,52 / \mathrm{km}$ rodado para os primeiros dois anos e $\mathrm{R} \$ 1,79 \mathrm{~km}$ em média após esse período. Também foi possível aferir outros resultados a partir da variação de utilização dos veículos, aumentando e diminuindo a média de quilometragem em projeções hipotéticas. Entretanto, cabe ressaltar que não houve na presente pesquisa análise qualitativa, tão pouco a verificação da efetividade do serviço de transporte. Trata-se apenas de um breve e inicial estudo quanto aos custos públicos, dentro dos parâmetros utilizados pela administração pública.

Conclui-se que a pesquisa atendeu aos objetivos propostos e que há economicidade na locação de veículos, principalmente nos primeiros dois anos de contrato, aferindo somente pela questão de menor custo médio do quilômetro $(\mathrm{CMe})$, quanto mais se utiliza o veículo, menor fica o seu custo e maior é a economia para o contrato analisado.

Em razão da importância do assunto para o desenvolvimento social e a baixa quantidade de pesquisa sobre o tema, mostra-se necessário desenvolver mais estudos para esclarecer com mais profundidade o complexo setor de transporte, de forma a atender efetivamente a necessidade pública com o menor custo possível.

\section{REFERÊNCIAS}

ATHAR, Raimundo Aben. Introdução à Contabilidade. São Paulo, Prentice Hall, 2005. BEUREN, I. M. Evolução Histórica Da Contabilidade De Custos. Contabilidade Vista \& Revista, belo Horizonte, v. 5, n. 1, p. 61-66, fev. 1993.

BORNIA, A. C. Análise gerencial de custos: aplicação em empresas modernas. 3. ed. são Paulo: atlas, 2010.

BRASIL. Lei no 6.404, de 15 dezembro de 1976. Diário Oficial [da] União, 17 de dez. 1976. Disponível em: <http://www.planalto.gov.br/ccivil_03/leis/L6404consol.htm>. Acesso em: 06/07/2017 as 21:

Constituição da República Federativa do Brasil. Brasília, DF: Senado Federal: Centro Gráfico, 1988. 
Congresso. Senado. Lei $\mathbf{N}^{\mathbf{0}} \mathbf{7 . 7 3 5}$, de 22 de fevereiro de $1989 \mathrm{n}^{\circ} 168^{\circ}$ da Independência e $101^{\circ}$ da República, de 22 de fevereiro de 1989. Conversão da MPV N 34, de 1989. Dispõe Sobre A Extinção de órgão e de Entidade Autárquica, Cria O Instituto Brasileiro do Meio Ambiente e dos Recursos Naturais Renováveis e Dá Outras Providências. Senado Federal, Disponível em: <http://www.planalto.gov.br/ccivil_03/leis/L7735.htm>. Acesso em: 29 jul. 2017.

Lei $\mathbf{N}^{\circ}$ 6.938, de 31 de agosto de $1981 \mathrm{n}^{\circ} 160^{\circ}$ da Independência e $93^{\circ}$ da República, de 31 de agosto de 1981. Dispõe Sobre A Política Nacional do Meio Ambiente, Seus Fins e Mecanismos de Formulação e Aplicação, e Dá Outras Providências. Brasília, Disponível em: <http://www.planalto.gov.br/ccivil_03/leis/L6938compilada.htm>. Acesso em: 29 jul. 2017.

BUGARIN, Paulo Soares. O Princípio Constitucional da Economicidade. Correio Braziliense, Brasília, 12 abr. 1999, s/p.

CARNEIRO, Juarez Domingues et al. Normas brasileiras de contabilidade: contabilidade aplicada ao setor público: NBCs T 16.1 a 16.11/ Conselho Federal de Contabilidade. Brasília: Conselho Federal de Contabilidade, 2012. Publicação eletrônica. [51] p. Disponível em: < http://portalcfc.org.br/wordpress/wpcontent/uploads/2013/01/Setor_P\%C3\%BAblico.pdf > Acesso em: 09 de junho de 2017.

CREPALDI, Silvio Aparecido. Curso Básico De Contabilidade: Resumo da teoria. São Paulo. editora Atlas S.A. 2013. ed. 7.

GIL, Antônio Carlos. Como Elaborar Projetos de Pesquisa. 4. ed. São Paulo: Atlas, 2002. $176 \mathrm{p}$.

HADDAD, Rosaura Conceição; MOTA, Francisco Glauber Lima. Contabilidade Pública. Brasília: Capes, 2010. 152 p. Florianópolis: Departamento de Ciências da Administração / UFSC.

KAPLAN, R.; COOPER, R. Custo e desempenho: administre seus custos para ser mais competitivo. são Paulo: Futura, 1998.

MACHADO, Nelson. Sistema De Informação De Custo: Diretrizes Para Integração Ao Orçamento Público e à Contabilidade Governamental. 2002. 221f. Tese (Doutorado em Controladoria e Contabilidade) - Programa de Pós-Graduação em Controladoria e Contabilidade, Universidade de São Paulo, São Paulo, 2002.

MACIEL, Andréia Marques. BONACIM, Carlos Alberto Grespan. VICARI, Paula Regina. Análise Contábil: Módulo 3.1. Riberão Preto. UniSEB, 2011. $1^{\text {a }}$ Edisão

MARTINS, Eliseu. Contabilidade De Custos. 9. ed. São Paulo: Atlas, 2003.

MEGLIORINI, E. Custos: análise e gestão. 3. ed. são Paulo: Pearson Prentice Hall, 2012.

NASCIMENTO, J. M. do, Custos: Planejamento, Controle e Gestão Na Economia Globalizada. 2. ed. São Paulo: Atlas, 2001.

PALVARINI, Bruno. Guia Referencial De Mensuração Do Desempenho Na Administração Pública. (In: Anais do III Congresso Consad em Gestão Pública, Painel 12) Brasília, março, 2010.

QUINTANA, Alexandre Costa; MACHADO, Daiane Pias. et. al. Contabilidade Pública. São Paulo: Editora Atlas, 1 ed. 2011. 
SAMUELSON, Paul A. Introdução a Análise Econômica. Rio de Janeiro: Livraria AGIR editora, 1975. $8^{\text {a }}$ Edição traduzida da $9^{a}$ edição em inglês.

SANTOS, J. J . Contabilidade e análise de custos: modelo contábil, Métodos de depreciação, abc: custeio baseado em atividades, análise atualizada de encargos sociais sobre salários. 5. ed. são Paulo: atlas, 2009.

SILVA, L. M. Contabilidade Governamental: um enfoque administrativo da nova contabilidade pública. 8. ed. São Paulo: Atlas, 2009.

SOUZA, Alceu; CLEMENTE, Ademir. Gestão De Custos: Aplicações Operacionais e Estratégicas, Exercícios Resolvidos e Propostos Com Utilização Do Excel. São Paulo: Atlas, 2007

WARREN, Carl S. et al. Fundamentos De Contabilidade: princípios. são Paulo: Cengage, 2010. ed. 22 